\title{
CHANGING POPULATION OF MENTAL HOSPITALS
}

\author{
BY \\ G. M. CARSTAIRS, W. L. TONGE, N. O'CONNOR, AND L. E. D. BARBER \\ Medical Research Council Unit for Research in Occupational Adaptation
}

A number of publications in recent years have pointed out that, as a result of alterations in the laws relating to the care of the insane, of new methods of treatment, and of the changing public attitude to mental illness, important changes have occurred during the last 25 years in the type of patient admitted to hospital, and in the average length of stay. Fitzgerald (1954), Norris (1952), and Harris and Norris (1954) dealt with different aspects of this phenomenon, and Shepherd (1954) analysed changes occurring in one circumscribed region after an interval of 15 years. Goldhamer and Marshall (1949) discussed age-specific hospitalization rates for 19th and 20th-century America. Their conclusions are expressed in hospitalization habits for different age groups in the areas and periods concerned. They suggest that increased hospital facilities for the aged rather than increased arteriosclerosis may account for recent upward trends. Most British medical superintendents in their annual reports have had occasion to comment on the accelerated changes in the numbers and composition of their hospital admissions during the past 5 years.

In order to gain a clearer picture of the consequences which these tendencies have upon the composition of the mental hospital population it is necessary to carry out a census. Such a census was reported for hospitals in the Birmingham area by Cross (1954) in a survey which took especial note of the age distribution of patients, their length of stay, and the degree of over-crowding in male and female wards. The most comprehensive investigation of this kind to date has been the Registrar-General's statistical review (1953) which included a census of of all patients resident in mental hospitals at the end of 1949. This provides a valuable base-line for comparison with subsequent national and regional observations.

In the present small-scale survey a census was taken, in four mental hospitals serving the London area, of all patients resident on July 12, 1954, patients' present age, length of stay, diagnosis on admission and, in the case of male patients, previous occupation being noted. These figures have been compared with the Registrar-General's findings for 1949.
There has been a realtive increase in the proportion of older patients among the resident population (Table I). This fact is sufficiently well-known to hospital medical staffs, but an analysis of the sub-groups of patients in which the changes of age-bias are most marked reveals some additional information.

TABLE I

PATIENTS ABOVE AND BELOW THE AGE OF 65 YEARS

\begin{tabular}{cc|c|c}
\hline \multirow{2}{*}{ Source of Data } & \multicolumn{2}{c}{ Percentage Patients } \\
\cline { 3 - 3 } & & Under 65 & Over 65 \\
\hline Registrar-General (1953) & & $72 \cdot 4$ & $27 \cdot 6$ \\
Four Mental Hospitals & $\ldots$ & $(104,763)$ & $(39,843)$ \\
& & $(6,044)$ & $(2,949)$ \\
\hline
\end{tabular}

$$
\chi^{2}=115 \cdot 5 ; n=1 ; P=0.001
$$

In the Registrar-General's returns there were more female than male patients $(1 \cdot 34$ to 1$)$. In the totals for our four hospitals this ratio was 1.53 to 1 $\left(\chi^{2}=37 \cdot 185 ; P=0 \cdot 001\right)$. It is questionable, however, whether the difference may not be attributable in part to local variation from the national average. Thus Cross found that in Birmingham hospitals in 1953 the female to male ratio was $1 \cdot 32$ to 1 , which corresponds more closely to the Registrar-General's figure.

A comparison between the present survey and the population of the hospitals in the four Metropolitan Regions in 1949 is more meaningful. In the RegistrarGeneral's 1949 Tables these figures are not given for total populations; but they are available for patients who on December 31, 1949, had been in hospital for one year or more (Table II).

TABLE II

PATIENTS IN HOSPITAL FOR ONE YEAR OR MORE

\begin{tabular}{|c|c|c|c|}
\hline Source of Data & & Males & Females \\
\hline Registrar-General (1953) & $\cdots$ & 18,621 & 28,536 \\
\hline Four Mental Hospitals & . & 2,920 & 4,660 \\
\hline
\end{tabular}

In the present survey the increase in the preponderance of females in the long-stay population 
is not significant when gross totals are considered. Among long-stay patients above the age of 65 , however, the female preponderance is significantly increased (Table III).

TABLE III

LONG-STAY PATIENTS OVER 65 YEARS OF AGE

\begin{tabular}{|c|c|c|}
\hline \multirow{2}{*}{ Source of Data } & \multicolumn{2}{|c|}{ Patients over 65 years of age } \\
\hline & Male & Female \\
\hline Registrar-General (1953) & 4,421 & 10,530 \\
\hline Four Mental Hospitals & 619 & 1,953 \\
\hline
\end{tabular}

$\chi^{2}=21 \cdot 73 ; n=1 ; P=0.001$.

Whereas other studies have been focussed upon admission rates and length of stay, the present paper is concerned chiefly with the composition of that part of the patient population which could be regarded as "long-stay", and in particular with chronic schizophrenics. Table IV compares the age distribution of patients in the four hospitals with that of long-stay patients in the Metropolitan Regions (Registrar-General, 1953). The grounds for including patients in the category of schizophrenia in the present survey are described below (p. 190).

In schizophrenia there is a trend upwards in age in patients of both sexes. This trend is also shown by the proportion of schizophrenics over 65 years of age: 13 and 9 per cent. for males, and 33 and 17 per cent. for females, in the present sample and in the Registrar-General's data respectively. Figures for non-schizophrenic psychoses do not show this change. This increase in the number of elderly schizophrenic patients is no doubt a reflection in part of increased admissions of old people into mental hospitals, but may also be due to the increased longevity of long stay-patients. In the hospitals visited, 87.7 per cent. of the male and 90.0 per cent. of the female schizophrenics had been resident for more than 2 years.

\section{Discharge Rate of Long-Stay Patients}

An examination was made of all discharges during the 12 months preceding the survey of patients who had been in hospital continuously for 2 or more years. Expressed as a percentage of the number of long-stay patients resident in each hospital, these discharges were 1.8 per cent. of male patients and 1.6 per cent. of female patients, 20 per cent. of the men discharged and 41 per cent. of the women required further care, and only 35 per cent. of the men and 23 per cent. of the women were known to have made a full social recovery. Information about the remainder was insufficient to permit assessment of their measure of social adjustment after leaving hospital. It was evident that the great majority of patients who remain in hospital continuously for 2 years continue in hospital for a long period, if not for life.

\section{Social Class}

A striking finding of the Registrar-General's survey, and one in accord with several previous studies (Faris and Dunham, 1939; Felix and Bowers, 1948; Clarke, 1949), was the observation that the prevalence of schizophrenia appeared to be greatest in the lowest social classes: for males between the ages of 25 and 34 admission rates for schizophrenia were over five times higher in Social Class V than in Social Class I. By using the individual's previous occupation it was possible to allocate 81 per cent. of the male patients in our survey to one of the Registrar-General's five social classes.

TABLE IV

PERCENTAGE AGE DISTRIBUTION OF LONG-STAY PATIENTS

\begin{tabular}{|c|c|c|c|c|c|c|c|c|c|c|c|}
\hline Sex & Age Group & . & $0-24$ & $25-34$ & $35-44$ & $45-54$ & $55-64$ & $65-74$ & $75-$ & $\begin{array}{c}\text { Un- } \\
\text { known }\end{array}$ & Total \\
\hline \multirow{3}{*}{ Male } & Total & $\begin{array}{l}\text { Registrar-General (1953) } \\
\text { Hospitals } \quad . .\end{array}$ & $\begin{array}{l}2 \cdot 17 \\
1 \cdot 54 \\
\end{array}$ & $\begin{array}{l}10 \cdot 63 \\
12 \cdot 12\end{array}$ & $\begin{array}{l}19 \cdot 67 \\
19 \cdot 21\end{array}$ & $\begin{array}{l}23 \cdot 14 \\
25 \cdot 79\end{array}$ & $\begin{array}{l}20 \cdot 26 \\
20 \cdot 14\end{array}$ & $\begin{array}{l}16 \cdot 43 \\
14 \cdot 79\end{array}$ & $\begin{array}{l}7 \cdot 30 \\
6 \cdot 4\end{array}$ & 0.41 & $\begin{array}{r}100.01 \\
99.99\end{array}$ \\
\hline & Schizophrenics* & $\begin{array}{l}\text { Registrar-General (1953) } \\
\text { Hospitals } \\
\end{array}$ & $\begin{array}{l}3 \cdot 05 \\
1 \cdot 80\end{array}$ & $\begin{array}{l}19 \cdot 17 \\
15 \cdot 61\end{array}$ & $\begin{array}{l}30 \cdot 24 \\
24 \cdot 56\end{array}$ & $\begin{array}{l}25 \cdot 5 \\
27 \cdot 57\end{array}$ & $\begin{array}{l}13 \cdot 16 \\
17 \cdot 09\end{array}$ & $\begin{array}{l}6.67 \\
9.93\end{array}$ & $\begin{array}{l}1 \cdot 85 \\
3 \cdot 44\end{array}$ & $\frac{0.45}{-}$ & $\begin{array}{l}100 \cdot 09 \\
100 \cdot 00\end{array}$ \\
\hline & Other Diagnoses & $\begin{array}{lcc}\text { Registrar-General (1953) } \\
\text { Hospitals } \quad . . & . . \\
\end{array}$ & $\begin{array}{l}1.55 \\
1.10\end{array}$ & $\begin{array}{l}4 \cdot 53 \\
6 \cdot 25\end{array}$ & $\begin{array}{l}12 \cdot 11 \\
10 \cdot 20\end{array}$ & $\begin{array}{l}21 \cdot 45 \\
22 \cdot 79\end{array}$ & $\begin{array}{l}25 \cdot 31 \\
25 \cdot 28\end{array}$ & $\begin{array}{l}23 \cdot 40 \\
22 \cdot 97\end{array}$ & $\begin{array}{l}11 \cdot 18 \\
11 \cdot 39\end{array}$ & $0 \cdot 37$ & $\begin{array}{l}99.90 \\
99.98\end{array}$ \\
\hline \multirow{3}{*}{ Female } & Total & $\begin{array}{l}\text { Registrar-General (1953) } \\
\text { Hospitals } \quad . .\end{array}$ & $\begin{array}{l}1 \cdot 22 \\
0 \cdot 88\end{array}$ & $\begin{array}{l}5 \cdot 26 \\
5 \cdot 30\end{array}$ & $\begin{array}{l}13 \cdot 00 \\
10 \cdot 60\end{array}$ & $\begin{array}{l}19 \cdot 80 \\
19 \cdot 72\end{array}$ & $\begin{array}{l}23 \cdot 64 \\
21 \cdot 58\end{array}$ & $\begin{array}{l}22 \cdot 57 \\
25 \cdot 06\end{array}$ & $\begin{array}{l}14 \cdot 33 \\
16 \cdot 85\end{array}$ & $\begin{array}{c}0 \cdot 18 \\
-\end{array}$ & $\begin{array}{r}100 \cdot 00 \\
99.99\end{array}$ \\
\hline & Schizophrenics* & \begin{tabular}{lcc}
\multicolumn{3}{l}{ Registrar-General (1953) } \\
Hospitals &. &. \\
\end{tabular} & $\begin{array}{l}2 \cdot 24 \\
1 \cdot 26\end{array}$ & $\begin{array}{r}11 \cdot 15 \\
7 \cdot 38\end{array}$ & $\begin{array}{l}22 \cdot 65 \\
13 \cdot 78\end{array}$ & $\begin{array}{l}26 \cdot 29 \\
22 \cdot 97\end{array}$ & $\begin{array}{l}20 \cdot 59 \\
22 \cdot 07\end{array}$ & $\begin{array}{l}12 \cdot 29 \\
21 \cdot 45 \\
\end{array}$ & $\begin{array}{r}4 \cdot 64 \\
11 \cdot 11\end{array}$ & $0 \cdot 15$ & $\begin{array}{r}100 \cdot 00 \\
100 \cdot 02\end{array}$ \\
\hline & Other Diagnoses & $\begin{array}{l}\text { Registrar-General (1953) } \\
\text { Hospitals } \quad .\end{array}$ & $\begin{array}{l}0.74 \\
0.43\end{array}$ & $\begin{array}{l}2 \cdot 51 \\
2 \cdot 79\end{array}$ & $\begin{array}{l}8.51 \\
6.77\end{array}$ & $\begin{array}{l}16 \cdot 78 \\
15 \cdot 81\end{array}$ & $\begin{array}{l}25 \cdot 07 \\
21 \cdot 01\end{array}$ & $\begin{array}{l}27 \cdot 36 \\
29 \cdot 44\end{array}$ & $\begin{array}{l}18 \cdot 84 \\
23 \cdot 76\end{array}$ & $0 \cdot 19$ & $\begin{array}{l}100 \cdot 00 \\
100 \cdot 01\end{array}$ \\
\hline
\end{tabular}


The distribution of members of each social class was examined for four populations:

(1) All males over 15 years in the County of London (1951 Census).

(2) Male admissions diagnosed as schizophrenic during 1949 (Registrar-General, 1953).

(3) Short-stay patients in the present survey, who were diagnosed as schizophrenic.

(4) Long-stay patients in the present survey, who were diagnosed as schizophrenic.

Social Classes I and II contribute a disproportionately small number of cases of schizophrenia. It is conceivable that many patients belonging to these two classes may obtain treatment outside the provisions of the health service, but this is unlikely to account for the whole of the trend. It seems probable, moreover, that practically all members of Social Classes III, IV, and V who require hospital treatment for a schizophrenic illness are treated under the National Health Service. In these classes both the figures of the Registrar-General and those of the present survey show a raised incidence of cases of schizophrenia in Social Classes IV and V.

After a thorough study of the prevalence of mental disorders in a circumscribed community, Hollingshead and Redlich (1953, 1954) and Redlich, Hollingshead, Roberts, Robinson, Freedman, and Myers (1953) claim to have demonstrated two facts for the town of New Haven, Conn.: that the type of psychiatric treatment offered to patients differs with social class; and that in consequence of inadequate treatment patients from the lower social classes have a worse prognosis than those from the upper classes. The results of the present inquiry do not appear to support this conclusion (Table V): the numbers in Social Class III are a little greater among long-stay than among short-stay patients, and the numbers in Social Classes IV and V are a little smaller. This difference may be attributable to the greater availability of treatment in Great Britain

TABLE V

PERCENTAGE DISTRIBUTION BY SOCIAL CLASS OF MALE SCHIZOPHRENIC PATIENTS OVER THE AGE OF 15

\begin{tabular}{|c|c|c|c|c|}
\hline \multirow{3}{*}{$\begin{array}{l}\text { Social } \\
\text { Class }\end{array}$} & \multirow{3}{*}{$\begin{array}{c}\text { Males } \\
\text { over } 15 \text { in } \\
\text { London } \\
\text { (Census, 1951) }\end{array}$} & \multicolumn{3}{|c|}{ Male Schizophrenics over 15} \\
\hline & & \multirow{2}{*}{$\begin{array}{c}\text { Admissions } \\
\text { during 1949 } \\
\text { (Registrar-General, } \\
\text { 1953) }\end{array}$} & \multicolumn{2}{|c|}{ Present Survey } \\
\hline & & & $\begin{array}{l}\text { Short-Stay } \\
\text { Patients }\end{array}$ & $\begin{array}{l}\text { Long-Stay } \\
\text {. Patients }\end{array}$ \\
\hline I & $4 \cdot 0$ & $1 \cdot 7$ & $1 \cdot 0$ & 0.9 \\
\hline II & $13 \cdot 0$ & $7 \cdot 4$ & $0 \cdot 3$ & $3 \cdot 7$ \\
\hline III & $54 \cdot 2$ & $46 \cdot 1$ & $44 \cdot 5$ & $50 \cdot 9$ \\
\hline IV & $11 \cdot 9$ & $16 \cdot 6$ & $16 \cdot 6$ & $12 \cdot 8$ \\
\hline $\bar{V}$ & $16 \cdot 9$ & $28 \cdot 2$ & $35 \cdot 2$ & $31 \cdot 6$ \\
\hline
\end{tabular}

since the introduction of the National Health Service.

Hollingshead and Redlich (1954) also showed that the mean age of schizophrenic subjects when first seen by a psychiatrist was inversely related to social class level. On this point the results of the present survey (Table VI) are not consistent, but the small numbers of patients in Social Classes I and II may explain the difference between the findings.

TABLE VI

MEAN AGE OF SCHIZOPHRENICS ACCORDING TO SOCIAL CLASS

\begin{tabular}{l|c|c}
\hline $\begin{array}{c}\text { Social } \\
\text { Class }\end{array}$ & $\begin{array}{c}\text { Hollingshead and Redlich } \\
(1954)\end{array}$ & Present Survey \\
\hline I and II & $29 *$ & $38 \cdot 4 \dagger$ \\
\hline III $\quad$. & 31 & $33 \cdot 9$ \\
\hline IV & $\ldots$ & 32 \\
\hline V & . & $33 \cdot 6$ \\
\hline
\end{tabular}

* Mean age of patients when first seen by a psychiatrist.

tMean age of patients on admission to hospital.

In attempting to relate information about patients' social environment to their psychiatric history, the crude sub-division of cases by social class is only the first step. The next step would be to examine the groups of occupations severally, in order to ascertain whether specific occupations are associated with an unusually high or low incidence of certain disorders. This will not be possible until the analysis of the 1951 Census has been completed and the distribution of males among various occupations for the County of London has been made available.

It. was possible, however, by using the figures given in the ONE per cent. Sample Tables of the 1951 Census (General Register Office, 1952) to derive approximate figures for the occupational distribution of male members of Social Class $\mathrm{V}$ in this area. When compared with the occupational distribution of schizophrenic patients of Social Class V in the present survey, the proportion of general unskilled labourers in each group was found to be very similar ( 75 per cent. of the total). Certain anomalies were apparent in some minor categories of work. For example, dock labourers, newspaper-sellers, and warehousemen contributed fewer schizophrenics than their numbers appeared to warrant; so also did the group of watchmen and caretakers. On the other hand, office cleaners, costers and hawkers, porters, and kitchen-hands contributed significantly more than their share of such cases. No explanation can be advanced for these indications of a differential association of schizophrenia with certain occupations, but they suggest a problem for future investigation. 


\section{Discussion}

Any survey based upon a scrutiny of existing records must be limited in its accuracy by the quality of information available. In the present study the patients' sex, present age, and age on admission could be determined without difficulty, but in respect of diagnosis and occupation numerous ambiguities arose. Slater (1935), reporting on a similar survey, drew attention to the need to transpose archaic diagnostic terminology into contemporary terms, if psychiatric populations were to be compared. This is particularly the case with patients admitted to hospital over 20 years ago. Alternative diagnoses were most common in cases which to-day would be classed as one of the forms of schizophrenia. For the purpose of the present survey, patients with the following diagnoses on admission were included under this heading: dementia praecox, dementia paranoides, delusional insanity, paranoia, paraphrenia, paranoid state (unless specifically associated with depressive or senile psychosis), schizophrenia simplex, hebephrenia, primary dementia. Also included were cases of epilepsy and mental defect with "superimposed schizophrenia". The diagnosis of "secondary dementia" was attached to a number of long-stay patients. Examination of case-notes made it plain that most of these were also cases of schizophrenia: they were arbitrarily classified as such except for a few patients who were over 65 years of age on admission, who were counted as senile. The same procedure was adopted in classifying patients diagnosed on admission as suffering from "confusional insanity".

Organic and affective disorders presented fewer problems of classification, although there was again a variety in types of nomenclature.

Mention has been made above of the difficulty experienced in allotting patients to their appropriate social class. The data available on hospital record cards consist of statements of the patients' previous occupations, from which they can in theory be assigned to one of five social classes by reference to the "Classification of Occupations" (General Register Office, 1951). The limitations of this crude form of classification have been clearly expressed by Logan (1954), who indicates alternative methods of categorizing a patients' social milieu. Logan concludes that occupation remains the best practicable criterion for such classification. The five social classes thus distinguished remain so relatively heterogeneous in composition that it is remarkable that they are able to indicate a differential incidence of schizophrenia in the lowest class. It must be remembered in this connexion that the recorded "previous occupation" in a number of cases repre- sents not the employment for which the patient was trained or in which he was originally engaged, but rather the last of a series of progressively lower jobs which he has held during the years of onset of his illness. This process is recognizable in only a few instances, but where it occurs it tends to give a downward bias to the determination of the social class of schizophrenic patients. It is felt that valid information about the influence of sociological factors upon the form and incidence of mental disorders must await a more exhaustive process of fact-finding than is possible in a survey based upon existing hospital records.

\section{SUMMARY}

(1) A census of patients resident in four Metropolitan Mental Hospitals was carried out, and the figures compared with similar census data in the Registrar-General's 1949 review (published 1953).

(2) Significant increases were noted in the preponderance of female over male patients, and the proportion of patients over 65 years of age.

(3) The female preponderance was found to be especially marked in patients over 65 .

(4) The increase of elderly patients in the "longstay" population was found to be most marked in those diagnosed as schizophrenic.

(5) The census confirmed the findings of previous surveys that a disproportionately large percentage of schizophrenic patients is drawn from the lower social classes.

(6) In contrast with a recent American study, social class was not found to be correlated with length of stay in hospital.

\section{REFERENCES}

Clark, R. E. (1949). Amer. J. Sociol., 54, 433.

Cross, K. W. (1954). British Journal of Preventive and Social Medicine, 8, 29.

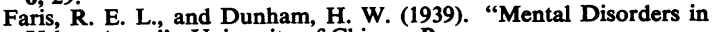
Urban Areas". University of Chicago Press.

Felix R. H., and Bowers, R. V. (1948). Milbank mem. Fd Quart. 26, 125.

Fitzgerald, O. (1954). Contribution to Symposium on Chronic Patients at a meeting of the Roy. med. Psychol. Ass., May 6, 1954. General Register Office (1951). "Classification of Occupations,

General Register Office (1951). "Classification of Occupations,
1950". H.M.S.O., London.
(1952). "Census 1951, Great Britain, ONE per cent. Sample Tables", part I. H.M.S.O., London.

Goldhamer, H., and Marshall, A. (1949). "Psychosis and Civilisation". Free Press, Glencoe, Ill.

Harris, A., and Norris, V. (1954). J. ment. Sci., 100, 241.

Hollingshead, A. B., and Redlich, F. C. (1953). Amer. sociol. Rev., 18, 163.

Logan, W, P. D. (1954). British Journal of Preventive and Social Medicine, $8,128$.

Norris, V. (1952). Lancet, 2, 1172.

Redlich, F. C., Hollingshead, A. B., Roberts, B. H., Robinson, H. A., Freedman, L. Z., and Myers, J. K. (1953). Amer. J. Psychiat., $109,729$.

Registrar-General (1953). "Statistical Review of England and Wales for the Year 1949: Supplement on General Morbidity, Cancer and for the Year 1949: Supplement on Gen

Shepherd, M. (1954). "A Study. of the Major Psychoses in an English County". D.M. Thesis, University of Oxford.

Slater, E. (1935). Ann. Eugen. (Cambs.), 6, 172. 